\title{
The Temperament Risk Factor, Disease Severity, and Quality of Life in Patients with Psoriasis
}

\author{
Konrad Janowski, Stanisława Steuden ${ }^{1}$ \\ Institute of Psychology, University of Economics and Human Sciences in Warsaw, Warsaw, ${ }^{1}$ Department of Clinical Psychology, John Paul \\ II Catholic University of Lublin, Lublin, Poland
}

\begin{abstract}
Background: Psoriasis exerts a profound negative impact on health-related quality of life (QoL). Although the severity of psoriasis is one potential variable that contributes to decreased QoL, previous studies have shown only weak or no association between measures of psoriasis severity and QoL. We hypothesized that this relationship is moderated by temperament factors. Objective: We aimed to verify whether the relationship between disease severity and QoL is moderated by a constellation of temperament traits (i.e., temperament risk factors) and whether this moderation takes place via cognitive-appraisal and coping processes. Methods: One hundred fifty patients with psoriasis vulgaris participated in the study. Psoriasis severity was assessed by a standardized measure, the Psoriasis Area and Severity Index (PASI), and the patients also completed a battery of psychological questionnaires assessing QoL, temperament, disease-related cognitive appraisals, and coping strategies. Results: A specific constellation of temperament traits was found to moderate the strength of the association between the PASI and QoL. This constellation of temperament traits was associated with certain disease-related cognitive appraisals (i.e., threat, obstacle/loss, harm, profit, value) and emotion-focused coping strategies (i.e., self-blame, avoidance, resignation, seeking
\end{abstract}

Received December 2, 2012, Revised March 21, 2014, Accepted for publication May 2, 2014

Corresponding author: Konrad Janowski, Institute of Psychology, University of Economics and Human Sciences in Warsaw, Okopowa 59, Warsaw 01043, Poland. Tel: 48-22-536-54-11, Fax: 48-22-536-54-08, E-mail: k.janowski @vizja.pl

ORCID: https://orcid.org/0000-0003-0838-9754

This is an Open Access article distributed under the terms of the Creative Commons Attribution Non-Commercial License (http://creativecommons. org/licenses/by-nc/4.0) which permits unrestricted non-commercial use, distribution, and reproduction in any medium, provided the original work is properly cited.

Copyright $\odot$ The Korean Dermatological Association and The Korean Society for Investigative Dermatology social support, and seeking information). Conclusion: The constellation of temperament traits is a crucial individual variable that strongly moderates the negative impact of psoriasis severity on QoL, potentially through the activation of nonadaptive cognitive appraisals and coping strategies in susceptible individuals. (Ann Dermatol 32(6) 452 459, 2020)

\section{-Keywords-}

Personality, Psoriasis, Quality of life, Temperament

\section{INTRODUCTION}

Psoriasis is a chronic, inflammatory, and noncontagious skin disease for which no cure is currently available. The typical course of psoriasis includes recurrent periods of aggravation and remission that are usually obtained after topical or systemic treatments are applied ${ }^{1-3}$. The clinical severity of psoriasis in a given person is difficult to assess because the lesions may differ considerably with respect to their morphological features and the body area they occupy. Therefore, a standardized observational scale-the Psoriasis Area and Severity Index (PASI)—-was developed ${ }^{4}$ and is commonly used by dermatologists to enable a more objective quantification of disease severity in a given person at a given point in time.

Psoriasis exerts a detrimental impact on the quality of life (QoL) of afflicted individuals ${ }^{5}$. Previous studies have shown that the extent to which psoriasis adversely affects QoL is related to various demographic, psychosocial, and clinical variables, including sex ${ }^{6}$, age ${ }^{7,8}$, alexithymia ${ }^{9}$, fear of negative evaluation ${ }^{10}$, coping skills ${ }^{11}$, illness perceptions ${ }^{12}$, depression $^{13}$, and disease duration ${ }^{14}$. However, ambiguous findings have been reported concerning the significance of psoriasis severity in compromising QoL. Some researchers 
have found that psoriasis patients' QoL was unrelated to disease severity as measured by the PASI ${ }^{15}$, whereas others have observed weak correlations between these variables $\left(0.16 \sim 0.28\right.$, depending on the QoL domain) ${ }^{10}$. This lack of unequivocal evidence for a significant and consistent association between psoriasis severity and QoL is surprising, as one would intuitively expect that more severe psoriasis would exert a more negative impact on QoL.

In an attempt to clarify this issue, we designed a study that allowed us to search for possible moderators of the relationship between psoriasis severity and QoL. In particular, we hypothesized that psychological factors may be potent buffers or facilitators of the impact of disease severity on QoL. In other words, we believe that psoriasis severity is significantly related to QoL but that this relationship can be weakened or enhanced by the individual psychological characteristics of a given patient.

Our hypothesis is consistent with the findings from research on human temperament indicating that temperament can be a crucial moderator of stress-related processes ${ }^{16-18}$. Temperament is an important aspect of personality and comprises basic, relatively stable traits that are responsible for individual differences in temporal and energetic aspects of behavior. The traits thought to be related to temperament are primarily determined by biological factors (e.g., general reactivity of the nervous system), and they remain relatively stable over a person's lifespan. The temperament traits that pertain to temporal aspects of behavior (i.e., briskness and perseverance) determine how quickly and for how long a person responds to stimuli. The temperament traits that pertain to energetic aspects of behavior (i.e., sensory sensitivity, emotional reactivity, endurance, and activity) determine a person's preference for stimulus intensity and how well the person tolerates situations that exceed his/her preferred level of activation (e.g., during stress). In this respect, temperament can exert psychophysiological costs when a person has to act under highly demanding stimuli ${ }^{19}$.

Some researchers have proposed that temperament moderates the negative effects of stressors; that is, certain temperament traits can act as a buffer for the consequences of stress, whereas other traits can facilitate those consequences $^{20,21}$. More specifically, Strelau ${ }^{20}$ has claimed that certain temperament traits or their configuration may constitute a temperament risk factor (TRF) that makes a person more vulnerable to the negative consequences of stress. The most likely mechanism accounting for this relationship would be the ability of the TRF to affect the cognitive appraisals people make when in a stressful situation and the coping strategies they undertake to manage stress ${ }^{22}$.

Cognitive appraisals and coping strategies are two key psychological processes that affect the consequences of a given stressful situation. Cognitive appraisals are the meanings people attribute to a given situation (e.g., whether a situation is threatening, harmful, or challenging). In turn, coping strategies are the various efforts people make to resolve a stressful situation (i.e., problem-focused strategies) or to ease the negative emotions they experience because of a stressful situation (i.e., emotion-focused strategies). When a stressor occurs, people may generate different cognitive appraisals and undertake diverse coping strategies, some of which may be highly adaptive and some of which may be maladaptive. Adaptive cognitive appraisals are those that help the person reduce the negative consequences of stress, and maladaptive cognitive appraisals and coping strategies are those that fail to protect the person from the negative consequences of stress ${ }^{23}$. The temperament traits that constitute the TRF may affect the scope of the consequences of stress through their impact on two psychological processes: cognitive appraisal and coping. If so, then the TRF should be associated with fewer adaptive cognitive appraisals attributed to the stressor (e.g., appraising the situation as a threat or harm) and with fewer adaptive strategies employed to cope with stress (e.g., resignation or avoidance) ${ }^{24}$.

We assumed that psoriasis is a stressor and that the levels of QoL are an indicator of the negative consequences of this stressor. This means that psoriasis severity objectively assessed by the PASI could be a measure of the intensity of the stressor, and the level of QoL could provide a measure of the negative consequences of this stressor. Temperament traits should, therefore, be shown to buffer or facilitate the relationship between psoriasis severity (PASI) and its consequences $(\mathrm{QoL})$. Indeed, in a preliminary report from this project, we have already demonstrated that particular temperament traits are powerful moderators of the relationship between psoriasis severity, as assessed by the PASI, and QoL. For instance, the correlations between the PASI and QoL were $r=0.60(p<0.001), r=0.27(p<0.05)$, and $r=-0.07$ (non-significant) for psoriasis patients with low, average, and high levels of endurance, respectively. In summary, we observed a significantly stronger relationship between psoriasis severity and QoL in patients with low to average briskness, sensory sensitivity, endurance, and activity and in patients with average to high perseverance and emotional reactivity ${ }^{25}$.

The objective of this study was to evaluate whether the TRF, understood as a specific configuration of temperament traits, moderates the strength of the relationship between disease severity (PASI) and QoL in patients with psoriasis vulgaris. Specifically, we addressed two questions: (1) Is it possible to identify a constellation of tem- 
perament traits that, when combined, constitute such a TRF? (2) If such a TRF does exist, does it affect the cognitive-appraisal and coping processes that mediate the stressor-stress relationship?

\section{MATERIALS AND METHODS}

\section{Participants}

One hundred fifty patients (60 female and 90 male) with psoriasis vulgaris took part in the study. The participants were recruited from several dermatology outpatient and inpatient clinics over a period of two months, and all were being treated for psoriasis. The mean $(M)$ age of the participants was 42.0 years (standard deviation [SD], 14.9 years), and the mean duration of the disease was 16.7 years (SD, 12.3 years). Twenty-one percent of the participants were outpatients, and $79 \%$ were inpatients. The diagnosis of psoriasis vulgaris was established or confirmed by a dermatologist upon admittance to the hospital or during a visit to an outpatient clinic. After the researcher provided a complete description of the study, written informed consent was obtained from all the participants. The participants were assessed with regard to the severity of their psoriasis and completed a battery of psychological tests under the supervision of a licensed clinical psychologist.

The study was approved by Ethical Committee at the University of Economics and Human Sciences in Warsaw (no. PSYCH/12/009).

\section{Procedure}

The PASI is a well-established standard dermatological measure of psoriasis severity that combines the severity of psoriasis symptoms (i.e., erythema, infiltration, and desquamation) and the percent of lesional skin into one numerical index. The evaluation is made by an observer, and scores are assigned for each of the symptoms for each of four body areas (head, trunk, upper limbs, and lower limbs). The scores are later computed in an equation with different weights for particular symptoms and body areas. The higher the PASI score, the more severe the psoriasis is in a given patient ${ }^{4}$.

The Skindex-29 is a self-report questionnaire developed by Chren et al. ${ }^{26}$ that measures QoL in patients with skin diseases. It consists of three subscales: Physical Symptoms, Functioning, and Emotions. The questionnaire had previously been adapted and validated in a Polish sample, and the results indicated very good psychometric properties resembling those reported for the original American version, with Cronbach's $\alpha$ reliability coefficient for the total score as high as $0.96^{27}$. Higher scores indicate a lower QoL. The Formal Characteristics of Behaviour-Temperament In- ventory (FCB-TI) was developed by Strelau and Zawadzki ${ }^{28}$ and is based on the regulative theory of temperament (RTT). It conceptualizes temperament in terms of the regulation of the temporal and energetic aspects of behavior ${ }^{29}$. It is a self-report questionnaire that measures six temperament traits: briskness, perseverance (pertaining to the temporal aspect of behavior), sensory sensitivity, endurance, emotional reactivity, and activity (pertaining to the energetic characteristics of behavior). The FCB-TI is a meticulously validated instrument with very high psychometric properties, demonstrated validity, and high reliability. Reliability coefficients range from 0.73 for sensory sensitivity to 0.85 for endurance. The raw scores obtained for each participant were transformed into the standard 9-point stanine (standard nine) scale according to the normative data from the questionnaire manual, and the scores were adjusted for age and $\operatorname{sex}^{28}$.

The Ways of Coping Questionnaire developed by Folkman et al. $^{23}$ has a validated Polish adaptation that we used to measure coping strategies. The Polish version of the questionnaire consists of 13 subscales that measure various coping strategies, including three problem-focused (gaining mastery, planful problem solving, and mobilization) and ten emotion-focused strategies (seeking information, seeking social support, resignation, self-blame, avoidance, distancing, compensating, religious coping, optimism, and positive reappraisal). Its reliability coefficients range from 0.50 for compensating to 0.82 for mobilization and avoidance $^{30}$.

The Disease-Related Appraisals Scale developed by Janowski et al. $^{31}$ is a self-report questionnaire designed to measure six modes of cognitive appraisals that are attributable to one's disease: threat, profit, obstacle/loss, challenge, harm, and value. The questionnaire also contains one control scale, importance, that measures the overall significance attributed to the disease. The reliability coefficients for particular subscales range from 0.70 for challenge to 0.90 for threat and obstacle/loss. The theoretical validity of the questionnaire was confirmed by factor analysis. The questionnaire was previously validated in various clinical groups, including samples of psoriasis patients ${ }^{31}$.

\section{Statistical analyses}

The results are presented as the $\mathrm{M} \pm \mathrm{SD}$. Associations between the PASI and QoL were calculated as Pearson's $r$ correlation coefficients. Cluster analysis using the $k$-means method was applied to identify the subgroups of participants with different constellations of temperament traits. Analysis of variance (ANOVA) was used to test the hypotheses regarding significant differences between the means of the three identified participant subgroups. Tukey's post 
hoc tests were applied to test for the significance of inter-group differences. The results were considered statistically significant at the level of $p<0.05$.

\section{RESULTS}

\section{Psoriasis severity and quality of life in the entire sample}

The mean PASI and Skindex-29 scores obtained for the entire sample are presented in Table 1. The PASI correlated statistically significantly $(p<0.001)$ with all three QoL dimensions ( $r=0.34$ for physical symptoms, $r=0.35$ for functioning, and $r=0.29$ for emotions) and with the QoL total score $(r=0.36)$. The correlation coefficients between the PASI and various dimensions of QoL were significant but relatively low.

\section{The constellation of temperament traits as a risk factor} for the relationship between the PASI and quality of life

We hypothesized that patients with psoriasis could be divided with respect to different temperament profiles (i.e., constellations of individual traits) that correspond to various levels of the TRF. To identify the constellation of temperament traits that may potentially constitute a TRF, we conducted a cluster analysis on the scores from the FCB-TI. As a result, three groups of participants were distinguished

Table 1. Means $(M)$ and standard deviations (SD) for the PASI and Skindex-29 scores obtained in the entire sample of patients with psoriasis $(n=150)$

\begin{tabular}{lcl}
\hline \multicolumn{1}{c}{ Measure } & Range & \multicolumn{1}{c}{$\mathrm{M} \pm \mathrm{SD}$} \\
\hline PASI & $0.8 \sim 47.2$ & $15.52 \pm 9.58$ \\
Skindex-29 (total) & $40 \sim 138$ & $91.16 \pm 24.46$ \\
Physical symptoms & $7 \sim 32$ & $20.85 \pm 5.42$ \\
Functioning & $12 \sim 59$ & $36.68 \pm 11.74$ \\
$\quad$ Emotions & $11 \sim 50$ & $33.63 \pm 9.86$ \\
\hline
\end{tabular}

PASI: Psoriasis Area and Severity Index.

Table 2. Mean scores of temperament traits as measured by the FCB-TI for each patients group identified in cluster analysis

\begin{tabular}{lccc}
\hline Temperament trait & $\begin{array}{c}\text { High-TRF } \\
\text { group } \\
(\mathrm{n}=45)\end{array}$ & $\begin{array}{c}\text { Moderate-TRF } \\
\text { group } \\
(\mathrm{n}=60)\end{array}$ & $\begin{array}{c}\text { Low-TRF } \\
\text { group } \\
(\mathrm{n}=45)\end{array}$ \\
\hline Briskness & $3.00 \pm 1.26$ & $4.87 \pm 1.76$ & $6.47 \pm 1.65$ \\
Perseverance & $5.89 \pm 1.37$ & $6.13 \pm 1.56$ & $3.87 \pm 1.32$ \\
Sensory sensitivity & $3.07 \pm 1.14$ & $5.72 \pm 1.62$ & $5.02 \pm 2.04$ \\
Emotional reactivity & $6.73 \pm 1.36$ & $5.83 \pm 1.29$ & $3.49 \pm 1.22$ \\
Endurance & $2.71 \pm 1.24$ & $4.25 \pm 1.32$ & $6.13 \pm 1.65$ \\
Activity & $4.11 \pm 1.56$ & $4.95 \pm 1.81$ & $5.93 \pm 1.36$ \\
\hline
\end{tabular}

Values are presented as mean \pm standard deviation. FCB-TI: Formal Characteristic of Behaviour-Temperament Inventory, TRF: temperament risk factor. by similar in-group and different inter-group temperament profiles. The mean scores for the temperament traits for each group are presented in Table 2, and group profiles are presented in Fig. 1.

Based on our previous analyses regarding the functional importance of separate temperament traits ${ }^{25}$, and as summarized in the Introduction, we hypothesized the probable levels of TRF for the subgroups identified in the cluster analysis. We labeled these subgroups as follows: High-TRF group $(n=45)$, Moderate-TRF group $(n=60)$, Low-TRF group $(n=45)$.

If the identified temperament-trait constellations do correspond to various levels of TRF, then we would expect the correlations between the PASI and QoL to differ across groups. Specifically, we expected that the High-TRF temperament profile would be related to a stronger correlation between the PASI and QoL. To verify this hypothesis, the correlation coefficients (Pearson's $r$ ) were calculated separately for each of the three temperament-profile groups. Consistent with our predictions, the correlations between the PASI and QoL were low and statistically insignificant in the Low-TRF group and increased according to the degree of TRF for the Moderate- and High-TRF groups (Table $3)$.

\section{Temperament risk factor and the cognitive-appraisal and coping processes}

The next step of our analyses aimed to verify whether the specific temperament-trait constellations moderate the relationship between disease severity (PASI) and QoL through

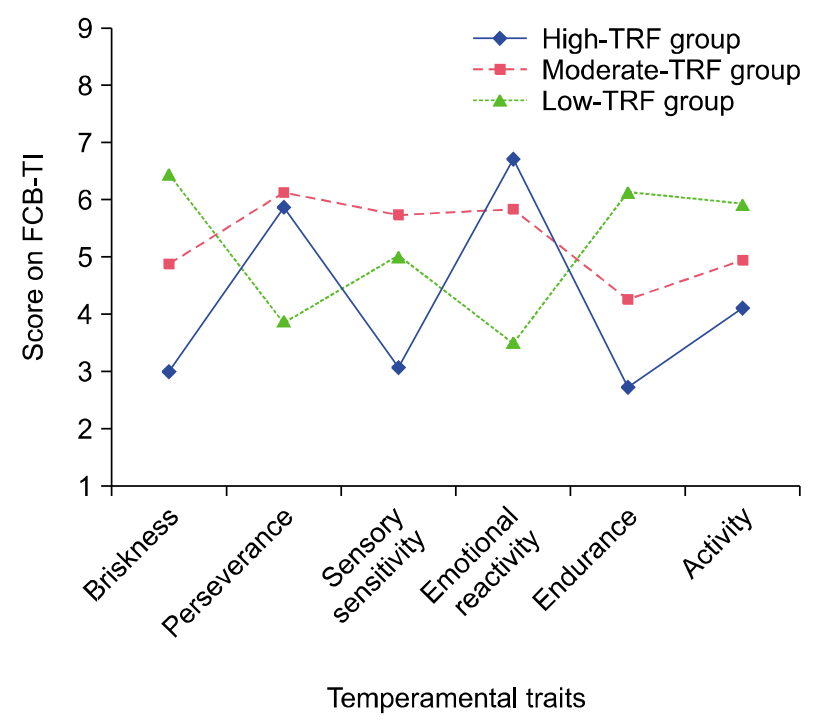

Fig. 1. Mean temperament profiles in the groups identified in cluster analysis. TRF: temperament risk factor, FCB-TI: Formal Characteristic of Behaviour-Temperament Inventory. 
Table 3. Pearson's $r$ correlations between the PASI and QoL in the groups of patients with various temperament profiles

\begin{tabular}{cccccc}
\hline Level of TRF & Psoriasis severity & Physical symptoms & Functioning & Emotions & QoL (total) \\
\hline High-TRF group $(\mathrm{n}=45)$ & PASI & $0.53^{* * *}$ & $0.50^{* * *}$ & $0.47^{* * *}$ & $0.55^{* * *}$ \\
Moderate-TRF group $(\mathrm{n}=60)$ & & $0.32^{*}$ & $0.41^{* * *}$ & $0.39^{* *}$ & $0.41^{* * *}$ \\
Low-TRF group $(\mathrm{n}=45)$ & & 0.29 & 0.19 & 0.08 & 0.21 \\
\hline
\end{tabular}

TRF: temperament risk factor, PASI: Psoriasis Area and Severity Index, QoL: quality of life. Statistically significant $\left({ }^{*} p<0.05,{ }^{* *} p<0.01\right.$, $* * *<0.001)$.

Table 4. Cognitive appraisals in the groups of patients with various temperament profiles

\begin{tabular}{lccccc}
\hline $\begin{array}{l}\text { Disease-Related } \\
\text { Appraisals }\end{array}$ & $\begin{array}{c}\text { High-TRF group } \\
(\mathrm{n}=45)\end{array}$ & $\begin{array}{c}\text { Moderate-TRF group } \\
(\mathrm{n}=60)\end{array}$ & $\begin{array}{c}\text { Low-TRF group } \\
(\mathrm{n}=45)\end{array}$ & \multicolumn{3}{c}{ ANOVA } \\
\cline { 5 - 7 } & & & & $\mathrm{F}$ & $p$-value \\
\hline Threat & $30.42 \pm 7.04$ & $27.05 \pm 8.46$ & $23.69 \pm 9.00$ & 7.52 & $0.001^{\mathrm{a}, \mathrm{b}, \mathrm{c}}$ \\
Profit & $15.96 \pm 6.50$ & $12.68 \pm 4.40$ & $12.31 \pm 3.79$ & 7.58 & $0.001^{\mathrm{a}, \mathrm{b}}$ \\
Obstacle/loss & $28.56 \pm 8.49$ & $25.45 \pm 8.52$ & $20.76 \pm 9.46$ & 8.99 & $0.000^{\mathrm{b}, \mathrm{c}}$ \\
Challenge & $21.71 \pm 4.58$ & $20.63 \pm 4.14$ & $21.16 \pm 5.84$ & 0.64 & 0.528 \\
Harm & $24.56 \pm 7.42$ & $20.37 \pm 7.20$ & $16.91 \pm 7.65$ & 12.05 & $0.000^{\mathrm{a}, \mathrm{b}, \mathrm{c}}$ \\
Value & $18.02 \pm 4.85$ & $15.68 \pm 4.91$ & $15.27 \pm 6.20$ & 3.69 & $0.029^{\mathrm{a}, \mathrm{b}}$ \\
Importance & $19.36 \pm 3.85$ & $19.22 \pm 4.79$ & $17.67 \pm 4.59$ & 2.06 & 0.131 \\
\hline
\end{tabular}

Values are presented as mean \pm standard deviation. TRF: temperament risk factor. Statistically significant differences between the following groups (post hoc tests): ${ }^{\mathrm{a}} \mathrm{High}-\mathrm{TRF}$ group-Moderate-TRF group, ${ }^{\mathrm{b}} \mathrm{High}-\mathrm{TRF}$ group-Low-TRF group, ${ }^{\mathrm{c}}$ Moderate-TRF group-Low-TRF group.

their impact on the processes mediating the stressor-stress effects relationship (i.e., the cognitive-appraisal and coping processes). In other words, we hypothesized that the TRF, conceptualized as the constellation of traits, would affect cognitive-appraisal and coping strategies. If there are differences in the modes of disease-related appraisals and coping strategies displayed by psoriasis patients with various degrees of TRF, then this could provide an explanation for the observed effects of the TRF on the PASI-QoL relationship. Therefore, we compared the three groups' scores from the Disease-Related Appraisals Scale and the Ways of Coping Questionnaire.

We found that the Moderate- and High-TRF groups tended to appraise the disease significantly more frequently in terms of threat, profit, obstacle, loss, harm, and value than the Low-TRF group. There were no significant differences between the three groups with respect to the appraisal of the disease as a challenge or the overall importance attributed to the disease (Table 4). With regard to coping strategies, the High-TRF group reported significantly more frequent use of emotion-focused strategies, including avoidance, self-blame, resignation, seeking social support, and seeking information, than the Moderate- and Low-TRF groups (Table 5).

\section{DISCUSSION}

Previous studies have yielded inconclusive data regarding the association between QoL and psoriasis severity. Some studies have not found a relationship between QoL and the $\mathrm{PASI}^{32}$, whereas others have reported relatively low contributions of disease severity to the decreased QoL. For example, Fortune et al. ${ }^{9}$ found that disease severity, as measured by the PASI, accounted for approximately $11 \%$ of the variance in psoriasis-related disability. In a few studies, the association between disease severity and QoL was of greater importance. For instance, Rapp et al..$^{33}$ found that disease-related variables accounted for $25 \%$ of the variance in QoL; however, to measure disease severity, a patient-generated version of the self-administered PASI was used, which may have augmented the associations with other subjective measures, such as QoL. In contrast, it is commonly accepted that improvements in the clinical severity of psoriasis are associated with better QoL and other indices of psychological functioning. For instance, Sampogna et al. ${ }^{34}$ demonstrated in a follow-up study that improvements in the clinical severity of psoriasis (as measured by the self-administered PASI) were associated with improvements in psychopathological symptoms.

In our study, the strength of the correlation between the PASI and the global QoL index was relatively weak for the entire sample of psoriasis patients (approximately $r=0.34$ 
Table 5. Coping strategies in the groups of patients with various temperament profiles

\begin{tabular}{|c|c|c|c|c|c|}
\hline \multirow{2}{*}{ Coping strategy } & \multirow{2}{*}{$\begin{array}{l}\text { High-TRF group } \\
\qquad(\mathrm{n}=45)\end{array}$} & \multirow{2}{*}{$\begin{array}{l}\text { Moderate-TRF group } \\
\qquad(n=60)\end{array}$} & \multirow{2}{*}{$\begin{array}{l}\text { Low-TRF group } \\
\qquad(\mathrm{N}=45)\end{array}$} & \multicolumn{2}{|c|}{ ANOVA } \\
\hline & & & & $\mathrm{F}$ & $p$-value \\
\hline Gaining mastery & $15.13 \pm 3.84$ & $15.72 \pm 3.07$ & $14.96 \pm 4.13$ & 0.64 & 0.530 \\
\hline Planful problem solving & $12.11 \pm 3.35$ & $11.67 \pm 3.37$ & $11.13 \pm 3.45$ & 0.94 & 0.394 \\
\hline Mobilization & $13.20 \pm 3.42$ & $13.52 \pm 3.21$ & $13.13 \pm 3.86$ & 0.19 & 0.830 \\
\hline Seeking information & $9.80 \pm 3.78$ & $9.00 \pm 2.93$ & $7.64 \pm 3.36$ & 4.84 & $0.009^{b, c}$ \\
\hline Seeking social support & $6.62 \pm 2.45$ & $5.95 \pm 2.37$ & $5.04 \pm 2.50$ & 4.78 & $0.010^{b}$ \\
\hline Resignation & $8.04 \pm 3.08$ & $5.40 \pm 2.72$ & $4.13 \pm 2.56$ & 23.22 & $0.000^{\mathrm{a}, \mathrm{b}, \mathrm{c}}$ \\
\hline Self-blame & $15.31 \pm 4.18$ & $11.93 \pm 3.93$ & $9.91 \pm 4.89$ & 18.10 & $0.000^{a, b, c}$ \\
\hline Avoidance & $16.18 \pm 5.73$ & $11.68 \pm 3.83$ & $9.24 \pm 4.60$ & 25.38 & $0.000^{a, b, c}$ \\
\hline Distancing & $4.49 \pm 1.87$ & $3.82 \pm 1.57$ & $4.47 \pm 1.62$ & 2.80 & 0.064 \\
\hline Compansating & $7.40 \pm 2.17$ & $6.80 \pm 2.00$ & $6.49 \pm 2.16$ & 2.21 & 0.114 \\
\hline Religious coping & $6.27 \pm 3.06$ & $5.38 \pm 2.95$ & $5.33 \pm 3.35$ & 1.40 & 0.265 \\
\hline Optimism & $4.96 \pm 1.92$ & $5.68 \pm 1.49$ & $5.33 \pm 1.86$ & 2.26 & 0.108 \\
\hline Positive reappraisal & $4.82 \pm 1.80$ & $4.20 \pm 1.80$ & $4.60 \pm 1.99$ & 1.52 & 0.222 \\
\hline Problem-focused strategies & $40.44 \pm 9.21$ & $40.90 \pm 8.36$ & $39.22 \pm 9.84$ & 0.45 & 0.637 \\
\hline Emotion-focused strategies & $67.84 \pm 16.66$ & $54.58 \pm 10.86$ & $46.93 \pm 15.44$ & 25.08 & $0.000^{\mathrm{a}, \mathrm{b}, \mathrm{c}}$ \\
\hline
\end{tabular}

Values are presented as mean \pm standard deviation. TRF: temperament risk factor. Statistically significant differences between the following groups (post hoc tests): ${ }^{\mathrm{a}} \mathrm{High}-\mathrm{TRF}$ group-Moderate-TRF group, ${ }^{\mathrm{b}} \mathrm{High}-\mathrm{TRF}$ group-Low-TRF group, ${ }^{\mathrm{c}}$ Moderate-TRF group-Low-TRF group.

for the total QoL score). However, we also observed that when the correlations between the PASI and QoL were analyzed according to different TRF levels (i.e., low, moderate, and high), the strength of the correlations increased with higher TRF levels. In the Low-TRF group, the correlation between the PASI and the QoL dimensions was low and not significant. In the Moderate-TRF group, the correlation increased to approximately 0.40 and was statistically significant. In the High-TRF group, the correlation increased to approximately 0.54 . Overall, these findings support the view that both separate traits and temperamenttrait constellations may constitute the TRF.

It is important to note that we did not pre-impose any particular solution for the cluster analysis, such as attempting to fit the clusters to pre-selected participants with specific profiles. The clusters yielded by the cluster analysis were independent of our previous assumptions on the "risk" levels of temperament traits, but they ultimately corresponded well to the trait constellations for a particular risk level. This finding points to the fact that, most likely, separate "high-risk" temperaments are not scattered randomly across individuals but rather tend to co-occur, or cluster, to produce the temperament profile constituting the TRF. In contrast, the temperament traits that posed a low risk tended to cluster together, yielding the Low-TRF temperament profile with generally protective effects.

Additionally, it is interesting that different QoL domains showed slightly different susceptibility to the moderating effect of the temperament-trait constellation on the rela- tionship between the PASI and QoL. The differences between the correlation coefficients for the Low and High-TRF groups were $0.23,0.31$, and 0.49 for physical symptoms, functioning, and emotions domains, respectively, indicating that the TRF is most potent in moderating the effects of psoriasis severity on the emotional aspects of QoL. The lowest moderating impact of temperament on the association between the PASI and the physical-symptoms QoL domain might be accounted for by the slightly overlapping variance shared by measures of the PASI and the physical symptoms subscale of the Skindex-29. However, even assuming a certain variance overlap, the moderating effects of temperament were also evident in this QoL domain.

In this study, we also wanted to test whether the TRF was related to cognitive appraisals and coping strategies. We found that the High-TRF group appraised their disease in terms of threat, profit, obstacle, loss, harm, and value significantly more frequently than the Moderate- and Low-TRF groups. The overall subjective importance of the disease, however, did not differ significantly between the groups. Moreover, a majority of the appraisals that differed between the High-TRF group and the Moderate- and Low-TRF groups could be argued to be non-adaptive (e.g., threat, obstacle, harm, profit).

The High-TRF group reported significantly more frequent use of the avoidance, self-blame, resignation, seeking social support, and seeking information coping strategies. Three of these strategies (avoidance, self-blame, and resig- 
nation) are unequivocally non-adaptive, and it is for these strategies that the High-TRF group showed the most significant differences from the other two groups. The remaining two strategies (seeking social support and seeking information) could be potentially adaptive, but when they co-occur with avoidance, self-blame, and resignation, they could also reflect an excessive need for dependence on others and be non-adaptive in the sense that they reduce the individual's potential for autonomous, self-reliant coping. It is also of note that the level of TRF was associated only with emotion-focused coping strategies and not with problem-focused coping strategies.

Overall, it seems plausible that the TRF determines lessadaptive cognitive appraisals attributed to the stressor (more threatening, more harmful, more disruptive) and influences the choice of less-adaptive coping strategies (emotionfocused strategies). Such a combination of cognitive appraisals and coping strategies is likely to be associated with more negative effects of the stressor (disease), which could be an explanation for the observed moderating effects of temperament on the relationship between psoriasis severity and QoL.

Interestingly, Yang et al. ${ }^{32}$ failed to find an association between psoriasis severity and QoL but observed that approximately $30 \%$ of the variance in the QoL of their psoriasis patients was explained by psychological variables. Our findings suggest that psychological variables such as temperament may impact QoL through moderation of the disease severity-QoL association. Temperament traits have previously been associated with QoL in other clinical groups, such as patients with schizophrenia ${ }^{35,36}$ and rheumatoid arthritis $^{37}$, but we failed to find further reports of the impact of temperament on the relationship between disease severity and QoL.

In summary, the findings of this study indicate that temperament is a crucial psychological (individual) variable that strongly moderates the negative impact of psoriasis severity on QoL. These findings may be helpful in better identification of those patients who are at greater risk for decreases in QoL if their psoriasis becomes more severe. Additionally, the current findings offer a new perspective on how improvement in most clinical trials is measured. Most studies use both measures of psoriasis severity and QoL as indices of clinical change after treatment. Our findings suggest that there is a subgroup of patients (characterized by low TRF) in whom an improvement in clinical severity of the disease may be unrelated to an improvement in QoL.

\section{CONFLICTS OF INTEREST}

The authors have nothing to disclose.

\section{FUNDING SOURCE}

A portion of this work was funded by a scholarship grant from the Polish Ministry of Science and Higher Education to Dr. Janowski.

\section{DATA SHARING STATEMENT}

The data that support the findings of this study are available from the corresponding author upon reasonable request.

\section{ORCID}

Konrad Janowski, https://orcid.org/0000-0003-0838-9754

Stanisława Steuden, https://orcid.org/0000-0003-0078-5613

\section{REFERENCES}

1. Wagner EF, Schonthaler HB, Guinea-Viniegra J, Tschachler E. Psoriasis: what we have learned from mouse models. Nat Rev Rheumatol 2010;6:704-714.

2. Griffiths CE, Barker JN. Pathogenesis and clinical features of psoriasis. Lancet 2007;370:263-271.

3. Zanni GR. Psoriasis: issues far more serious than cosmetic. Consult Pharm 2012;27:86-96.

4. Fredriksson T, Pettersson U. Severe psoriasis: oral therapy with a new retinoid. Dermatologica 1978;157:238-244.

5. Bhosle MJ, Kulkarni A, Feldman SR, Balkrishnan R. Quality of life in patients with psoriasis. Health Qual Life Outcomes 2006;4:35.

6. Richards HL, Fortune DG, Griffiths CE, Main CJ. The contribution of perceptions of stigmatisation to disability in patients with psoriasis. J Psychosom Res 2001;50:11-15.

7. Gupta MA, Gupta AK. Age and gender differences in the impact of psoriasis on quality of life. Int J Dermatol 1995;34: 700-703.

8. Sampogna F, Chren MM, Melchi CF, Pasquini P, Tabolli S, Abeni D. Age, gender, quality of life and psychological distress in patients hospitalized with psoriasis. Br J Dermatol 2006; 154:325-331.

9. Fortune DG, Richards HL, Griffiths CE, Main CJ. Psychological stress, distress and disability in patients with psoriasis: consensus and variation in the contribution of illness perceptions, coping and alexithymia. Br J Clin Psychol 2002; 41(Pt 2):157-174.

10. Leary MR, Rapp SR, Herbst KC, Exum ML, Feldman SR. Interpersonal concerns and psychological difficulties of psoriasis patients: effects of disease severity and fear of negative evaluation. Health Psychol 1998;17:530-536. 
11. Wahl A, Hanestad BR, Wiklund I, Moum T. Coping and quality of life in patients with psoriasis. Qual Life Res 1999; 8:427-433.

12. Scharloo M, Kaptein AA, Weinman J, Bergman W, Vermeer BJ, Rooijmans HG. Patients' illness perceptions and coping as predictors of functional status in psoriasis: a 1-year follow-up. Br J Dermatol 2000;142:899-907.

13. Schmitt JM, Ford DE. Role of depression in quality of life for patients with psoriasis. Dermatology 2007;215:17-27.

14. Unaeze J, Nijsten T, Murphy A, Ravichandran C, Stern RS. Impact of psoriasis on health-related quality of life decreases over time: an 11-year prospective study. J Invest Dermatol 2006; 126:1480-1489.

15. Fortune DG, Main CJ, O'Sullivan TM, Griffiths CE. Quality of life in patients with psoriasis: the contribution of clinical variables and psoriasis-specific stress. Br J Dermatol 1997; 137:755-760.

16. Strelau J. The role of temperament as a moderator of stress. In: Wachs TD, Kohnstamm GA, editors. Temperament in context. Mahwah (NJ): Erlbaum Associates, 2001:153-172.

17. Stansbury K, Harris ML. Individual differences in stress reactions during a peer entry episode: effects of age, temperament, approach behavior, and self-perceived peer competence. J Exp Child Psychol 2000;76:50-63.

18. Finch JF, Graziano WG. Predicting depression from temperament, personality, and patterns of social relations. J Pers 2001;69:27-55.

19. Strelau J. Temperament: a psychological perspective. New York: Plenum Press, 1998.

20. Strelau J. Temperament risk factor: the contribution of temperament to the consequences of the state of stress. In: Hobfoll S, de Vries M, editors. Extreme stress and communities: impact and intervention. Dordrecht: Kluwer Academic Publishers, 1995:63-81.

21. Carey WB. Introduction: basic issues. In: Carey WB, MacDevitt SC, editors. Clinical and educational applications of temperament research. Amsterdam: Swets and Zeitlinger, 1989:11-20.

22. Strelau J. Temperament and stress: temperament as a moderator of stressors, emotional states, coping, and costs. In: Spielberger CD, Sarason IG, Brebner JMT, Greenglass E, Laungani $\mathrm{P}, \mathrm{O}^{\prime}$ Roark AM, editors. Stress and emotion: anxiety, anger, and curiosity. Washington: Taylor and Francis, 1995:215-254.

23. Folkman S, Lazarus RS, Dunkel-Schetter C, DeLongis A, Gruen RJ. Dynamics of a stressful encounter: cognitive appraisal, coping, and encounter outcomes. J Pers Soc Psychol 1986;50:992-1003.

24. Strelau J. Temperament as a moderator of coping with stress. In: Battmann W, Dutke S, editors. Processes of the molar regulation of behavior. Lengerich: Pabst Science Publishers, 1996:205-217.

25. Janowski K, Steuden S. Severity of psoriasis and health-related quality of life: the moderating effects of temperament. Br J Dermatol 2008;158:633-635.

26. Chren MM, Lasek RJ, Flocke SA, Zyzanski SJ. Improved discriminative and evaluative capability of a refined version of Skindex, a quality-of-life instrument for patients with skin diseases. Arch Dermatol 1997;133:1433-1440.

27. Janowski K, Steuden S, Bereza B. The Polish version of Skindex-29: psychometric properties of an instrument to measure quality of life in dermatology. Postepy Dermatol Alergol 2014;31:12-20.

28. Strelau J, Zawadzki B. The Formal Characteristics of Behaviour- Temperament Inventory (FCB-TI): validity studies. Eur J Pers 1995;9:207-229.

29. Strelau J. The regulative theory of temperament: current status. Pers Individ Differ 1996;20:131-142.

30. Oleś P. [The 'mid-life' crisis in men. A psychological empirical study]. Lublin: Redakcja Wydawnictw KUL, 1995. Polish.

31. Janowski K, Steuden S, Kuryłowicz J, Nieśpiałowska-Steuden M. The Disease-Related Appraisals Scale: a tool to measure subjective perception of the disease situation. In: Janowski K, Steuden S, editors. Biopsychosocial aspects of health and disease. Vol. 1. Lublin: CPPP Scientific Press, 2009:108-125.

32. Yang Y, Koh D, Khoo L, Nyunt SZ, Ng V, Goh CL. The psoriasis disability index in Chinese patients: contribution of clinical and psychological variables. Int J Dermatol 2005; 44:925-929.

33. Rapp SR, Cottrell CA, Leary MR. Social coping strategies associated with quality of life decrements among psoriasis patients. Br J Dermatol 2001;145:610-616.

34. Sampogna F, Tabolli S, Abeni D. The impact of changes in clinical severity on psychiatric morbidity in patients with psoriasis: a follow-up study. Br J Dermatol 2007;157:508513.

35. Kurs R, Farkas H, Ritsner M. Quality of life and temperament factors in schizophrenia: comparative study of patients, their siblings and controls. Qual Life Res 2005; 14:433-440.

36. Ritsner M, Farkas $H$, Gibel A. Satisfaction with quality of life varies with temperament types of patients with schizophrenia. J Nerv Ment Dis 2003;191:668-674.

37. Chou CY, Brauer DJ. Temperament and satisfaction with health status among persons with rheumatoid arthritis. Clin Nurse Spec 2005;19:94-100. 